\title{
Abatacept retention and clinical outcomes in rheumatoid arthritis: real-world data from the German cohort of the ACTION study and a comparison with other participating countries
}

\author{
Rieke Alten ${ }^{1}\left(\mathbb{D} \cdot\right.$ Eugen Feist $^{2} \cdot$ Hanns-Martin Lorenz ${ }^{3} \cdot$ Hubert Nüßlein $^{4} \cdot$ Reinhard E. Voll $^{5} \cdot$ Melanie Chartier $^{6}$. \\ Yedid Elbez ${ }^{7} \cdot$ Christiane Rauch $^{8}$
}

Received: 1 February 2019 / Revised: 10 June 2019 / Accepted: 17 June 2019/Published online: 12 July 2019

(C) The Author(s) 2019

\begin{abstract}
Introduction AbataCepT In rOutiNe clinical practice (ACTION; NCT02109666) was an observational study of patients with rheumatoid arthritis who initiated intravenous abatacept in clinical practice. We aimed to compare abatacept retention rates and clinical outcomes in patients from Germany versus other countries.

Method Baseline characteristics, crude retention rates, and clinical outcomes were compared by treatment line in the German cohort at 2 years. In addition, biologic-naïve patients were compared with biologic-naïve patients pooled from other participating countries.

Results In the German cohort, 677/680 (99.6\%) patients enrolled were evaluable and 171/677 (25.3\%) were biologic naïve. At baseline, abatacept monotherapy was received by a similar proportion of biologic-naïve and biologic-failure patients in the German cohort, but by a greater proportion of biologic-naïve patients in German versus other countries cohort (27.5 vs. $12.9 \%$ ). The overall crude abatacept retention rate at 2 years in the German cohort was 39.9\%; retention rate did not differ significantly by treatment line, but among biologic-naïve patients it was lower in Germany than in the other countries cohort (42.1 vs. $58.7 \%$; log-rank test $p<0.001)$. At 2 years, good/moderate European League Against Rheumatism (EULAR) response rates in biologic-naïve patients were $85.5 \%$ in the German and $92.1 \%$ in other countries cohort $(p=0.163)$.

Conclusions In the German cohort of ACTION, abatacept retention at 2 years was similar in biologic-naïve and biologic-failure patients. Biologic-naïve patients in German cohort had a significantly lower abatacept retention rate and a trend of lower good/ moderate EULAR response rate than those in the other countries cohort.

\section{Key Points}

- Analyses of data from national patient cohorts provide insight on local treatment patterns.

- In the German cohort of the ACTION study, abatacept retention at 2 years was similar in biologic-naïve and biologic-failure patients.

- Biologic-naïve patients from the German cohort had a significantly lower abatacept retention rate and a trend of lower good/ moderate EULAR response rate than patients from other countries.

- Data from large international studies may not be directly applicable to individual countries.
\end{abstract}

Electronic supplementary material The online version of this article (https://doi.org/10.1007/s10067-019-04648-5) contains supplementary material, which is available to authorized users.

\section{Rieke Alten}

rieke.alten@schlosspark-klinik.de

1 Department of Internal Medicine II, Rheumatology, Clinical Immunology and Osteology, Schlosspark-Klinik University Medicine Berlin, Heubnerweg 2, 14059 Berlin, Germany

2 Charité Universitaetsmedizin Berlin, Berlin, Germany

3 University Hospital, Heidelberg, Germany
4 University of Erlangen-Nuremberg, Nuremberg, Germany

5 Medical Center - University of Freiburg, Faculty of Medicine, University of Freiburg, Freiburg, Germany

6 Bristol-Myers Squibb, Rueil-Malmaison, France

7 Excelya, Boulogne-Billancourt, France

8 Bristol-Myers Squibb, Munich, Germany 
Keywords Biologic-failure patients $\cdot$ Biologic-naïve patients $\cdot$ Clinical practice $\cdot$ Germany $\cdot$ Rheumatoid arthritis

\section{Introduction}

Rheumatoid arthritis (RA) is a chronic, autoimmune, inflammatory disease causing progressive joint damage and subsequently impaired physical function, and requires long-term management. Treatment of RA includes both conventional synthetic disease-modifying antirheumatic drugs (csDMARDs), the most widely used of which is methotrexate, and biologic (bDMARDs), predominantly tumor necrosis factor inhibitors (TNFis) [1]. Current treatment guidelines for RA recommend a "treat-to-target" principle to achieve remission or low disease activity (LDA) [2]. While adherence and continuation of antirheumatic therapy are necessary to achieve optimal outcomes, real-world studies have reported discontinuation rates for TNFi therapy of $30-50 \%$ at 2 years [3]. Factors influencing adherence and continuation of therapy include treatment response and safety or tolerability, and there is considerable interest in identifying patient and disease characteristics that may influence efficacy and safety in individual patients.

While randomized controlled trials for biologic agents have contributed a wealth of efficacy and safety data, some patients with RA do not meet the stringent inclusion criteria (e.g., age, comorbid conditions, and active disease measurement requirements) for such trials, thereby reducing their generalizability. As such, real-world data supplement evidence from interventional studies by providing clinically relevant and valuable insights into bDMARD use in representative and heterogeneous patient populations. In addition, differences between countries are important considerations when analyzing data from international studies. It has been reported that variations in patient characteristics, prescribing or health-care system reimbursement may have contributed to the geographical differences in response to and retention of the selective T cell co-stimulation modulator abatacept in patients with RA reported previously [4]. Notably, it was shown that greater accessibility to bDMARDs was associated with lower abatacept retention [4].

AbataCepT In rOutiNe clinical practice (ACTION) was a 2-year, observational, prospective study of patients with moderate-to-severe RA who initiated intravenous abatacept therapy during routine clinical practice [4-7]. The study was carried out across Europe (Austria, Belgium, Czech Republic, Denmark, France, Germany, Greece, Italy, Netherlands, Spain, and Switzerland) and Canada from May 2008 to December 2013 and included patients who initiated abatacept as a first-, second-, or further-line biologic. In the overall ACTION study population, higher abatacept retention rates were seen in earlier versus later lines of treatment; however, variations by country have been noted [4, 8]. Notably, biologic-naïve patients in Canada, Greece, and Italy were found to be less likely to discontinue treatment at 2 years than those in
Germany [8]. Therefore, to provide a real-world, local perspective and to explore differences between Germany and other countries further, we report the results of a 2-year post hoc analysis of retention rates and clinical outcomes by treatment line in the German cohort of patients enrolled in the ACTION study. We also compare outcomes in biologicnaïve patients from Germany with those in the pooled cohort of biologic-naïve patients from other countries in ACTION.

\section{Materials and methods}

\section{Study design, patients, and treatment}

ACTION (ClinicalTrials.gov identifier, NCT02109666) was a 2-year, prospective, observational, international study. The ACTION study design, including the three enrollment periods and eligibility criteria, has been described in detail previously (Fig. 1) [5]. Briefly, patients aged $\geq 18$ years with moderateto-severe RA (American College of Rheumatology revised criteria 1987) [9] who initiated intravenous abatacept in routine clinical practice at their clinician's discretion as first- (biologic naïve) or second-/further-line (biologic failure) therapy were eligible. Treatment was in accordance with summary of product characteristics in Europe [10] or the product monograph in Canada [11]. Follow-up visits were approximately every 3 months for up to 30 months.

The analysis population reported here comprised biologicnaïve and biologic-failure patients who were enrolled in Germany between May 2008 and December 2013. As biologic-naïve patients were the primary focus of this analysis, the biologic-failure patients were pooled regardless of number of prior failures. To explore regional differences further, outcomes in biologic-naïve patients in the German cohort were also compared with pooled data from biologic-naïve patients enrolled in other countries in ACTION (Austria, Belgium, Canada, Czech Republic, Denmark, France, Greece, Italy, Netherlands, Spain, and Switzerland).

The study was conducted in accordance with the Declaration of Helsinki [12], the International Conference for Harmonization Guideline for Good Clinical Practice [13], and the Good Epidemiological Practice guideline [14], with local institutional review board/independent ethics committee approval. All patients provided written informed consent in accordance with local laws.

\section{Assessments}

Patient demographics and disease characteristics were assessed at baseline. The primary endpoint was crude 


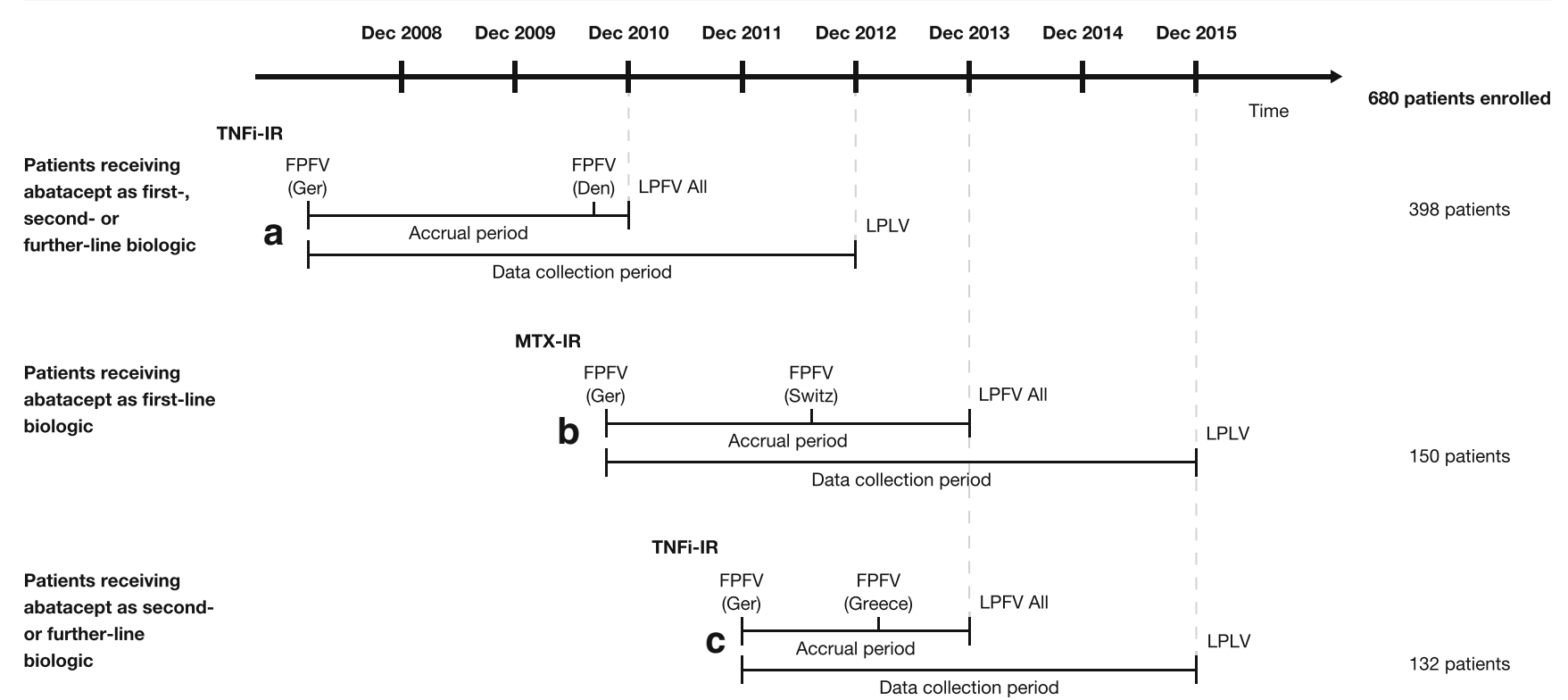

Fig 1 ACTION study design showing patient enrollment in the German cohort. Den, Denmark; Ger, Germany; TNFi, tumor necrosis factor inhibitor; FPFV, first patient first value; IR, inadequate response; LPFV,

abatacept retention rate (defined as consecutive time on treatment) over 2 years. Analyses were initially performed for patients in the German cohort only, comparing biologicnaïve and biologic-failure subgroups. Further analyses of the biologic-naïve patients compared data from those in the German cohort with those pooled from the other countries participating in ACTION.

Clinical efficacy of abatacept at 2 years was assessed using the European League Against Rheumatism (EULAR) response criteria based on Disease Activity Score in 28 joints (DAS28 [erythrocyte sedimentation rate; ESR, otherwise Creactive protein; $\mathrm{CRP}]$ ). The following assessments of disease activity were also performed: DAS28 remission (ESR or CRP; $<2.6)$, Clinical Disease Activity Index (CDAI) LDA $(<10.0)$ or remission $(\leq 2.8)$, Simplified Disease Activity Index (SDAI) LDA $(\leq 11.0)$ or remission $(\leq 3.3)$, and Boolean response (tender joint count $[\mathrm{TJC}] \leq 1$, swollen joint count $[\mathrm{SJC}] \leq 1, \mathrm{CRP} \leq 1 \mathrm{mg} / \mathrm{dL}$, and patient global assessment $[\mathrm{PGA}] \leq 1$ [on a $0-10$ scale]) [15].

Safety was assessed throughout the study in accordance with local regulations. Adverse events (AEs) were assessed by the treating physician and registered with the drug manufacturer's global pharmacovigilance department. All AEs, serious AEs (SAEs), discontinuations due to AEs, and AEs of special interest (including those associated with immunomodulatory drug use, such as infections, prespecified autoimmune disorders, malignancies, and infusion reactions) were recorded.

\section{Statistical analyses}

Patient demographics and disease characteristics at baseline were reported descriptively and presented as sample last patient first value; LPLV, last patient last value; MTX, methotrexate; Switz, Switzerland

size, mean (SD) values for continuous variables, and frequency (percentage) values for categorical variables. Crude abatacept retention rates (overall and by treatment line) with corresponding 95\% confidence intervals (CIs) were estimated by Kaplan-Meier analysis and were compared using log-rank tests by treatment line (biologic naïve, 1 or $\geq 2$ prior biologic failures), and for biologic-naïve patients in Germany versus those pooled from the other participating countries. Clinical outcomes including good/moderate EULAR response rates were compared by Fisher's exact tests. The frequencies of AEs were summarized descriptively.

\section{Results}

\section{Patients}

Among the overall ACTION cohort $(N=2350), 680$ $(28.9 \%)$ patients were recruited in Germany, of whom $677(99.6 \%)$ were evaluable at 2 years. In the German cohort, $171 / 677(25.3 \%)$ patients were biologic naïve and $506 / 677(74.7 \%)$ had failed $\geq 1$ prior biologic (1 biologic 197/506 [38.9\%] patients; $\geq 2$ biologics 309/ 506 [61.1\%] patients; Fig. 2). In the pooled cohort from other countries, 502/1673 $(30.0 \%)$ patients were biologic naïve and $1171 / 1673(70.0 \%)$ had failed $\geq 1$ prior biologic. The baseline demographic and disease characteristics of the overall patient population of ACTION and the biologic-naïve German and other countries cohorts are summarized in Table 1. 


\section{Enrolled N $=680$}

\begin{tabular}{|lr|}
\hline \multicolumn{2}{|l|}{ Patients excluded $\mathrm{n}=3(0.4 \%)$} \\
$\begin{array}{l}\text { Change in diagnosis } \\
\text { during follow-up }\end{array}$ & $\mathrm{n}=1$ \\
Enrolled retrospectively & $\mathrm{n}=1$ \\
$\begin{array}{l}\text { Switched to SC before } \\
\text { or the day of first IV }\end{array}$ & $\mathrm{n}=1$ \\
\hline
\end{tabular}

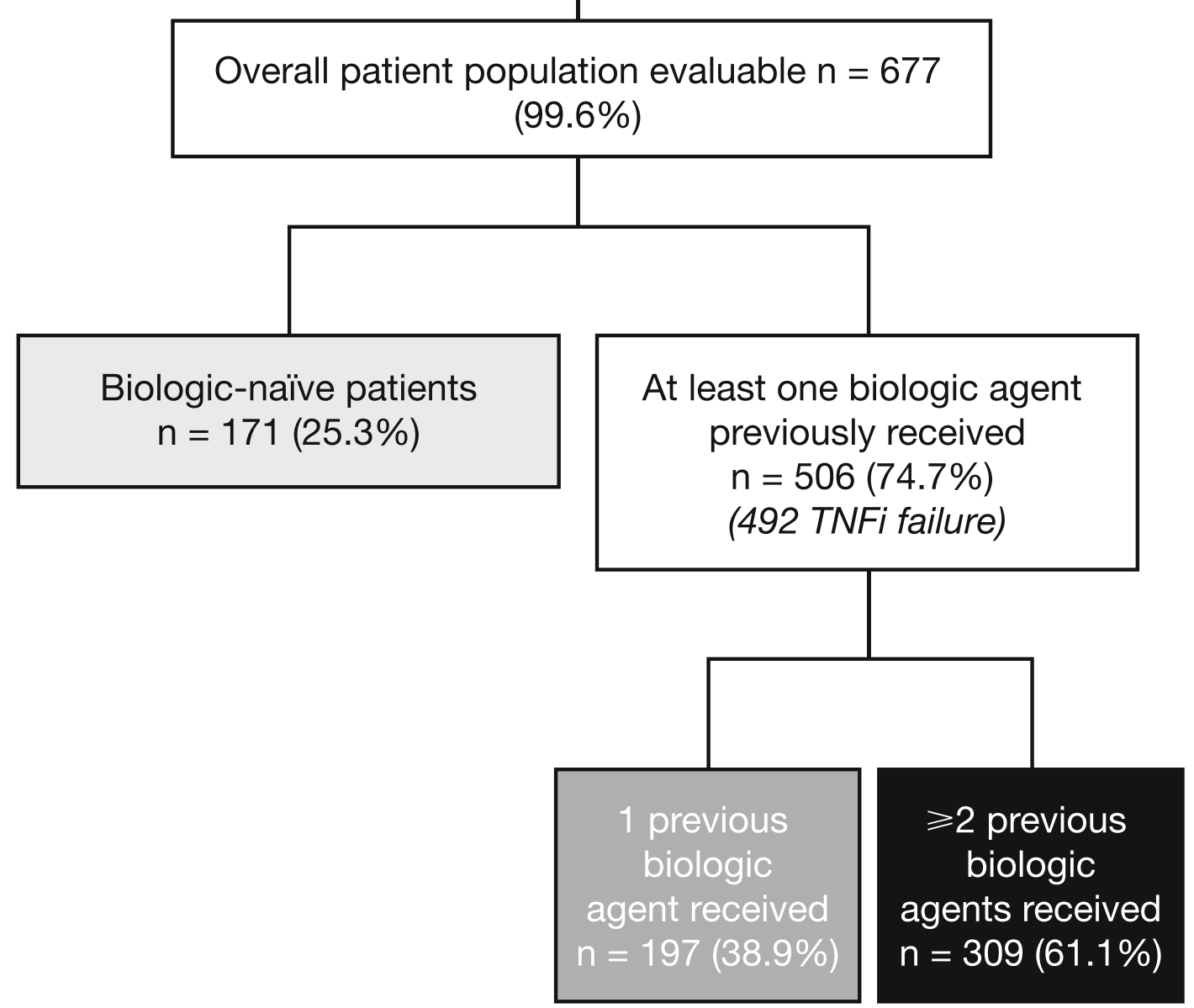

Fig. 2 Patient disposition for the German cohort. TNFi, tumor necrosis factor inhibitor; IV, intravenous; SC, subcutaneous. *Patient enrolled retrospectively within 3 months of initiation and authorized by the local ethics committee

\section{German cohort: biologic naïve versus biologic failure}

In the German cohort, for biologic-naïve versus biologicfailure patients, respectively, at baseline, biologic-naïve patients had a shorter mean (SD) duration of RA (7.5 [7.3] vs. 11.9 [8.6] years), with more having $\leq 2$ years' duration (26.5 vs. $8.1 \%$ ), and had received fewer prior
csDMARDs (mean [SD] number of csDMARDs: 1.43 [1.03] vs. 1.91 [1.31]); a smaller proportion of patients had radiographic erosions (57.6 vs. $76.7 \%$ ), but a higher proportion had one or more baseline comorbidities (83.0 vs. $76.1 \%$ ). Similar proportions of biologic-naïve and biologic-failure patients initiated abatacept monotherapy: 27.5 and $28.3 \%$, respectively. 
Table 1 Patient demographics and baseline disease characteristics in the overall population, German cohort, and other countries cohort of ACTION

\begin{tabular}{|c|c|c|c|c|c|c|}
\hline \multirow[b]{2}{*}{ Characteristic } & \multicolumn{2}{|l|}{$\begin{array}{l}\text { Overall } \\
(N=2350)\end{array}$} & \multirow{2}{*}{$\begin{array}{l}\text { Other countries } \\
\text { cohort } \\
(n=1673) \\
\text { Biologic naïve } \\
(n=502)\end{array}$} & \multicolumn{2}{|l|}{$\begin{array}{l}\text { German cohort } \\
(n=677)\end{array}$} & \multirow{2}{*}{$\begin{array}{l}\text { Other countries vs } \\
\text { German cohort } \\
P \text { value } \\
\text { Biologic naïve }\end{array}$} \\
\hline & $\begin{array}{l}\text { Biologic } \\
\text { naïve } \\
(n=673)\end{array}$ & $\begin{array}{l}\text { Biologic } \\
\text { failure } \\
(n=1677)\end{array}$ & & $\begin{array}{l}\text { Biologic naïve } \\
(n=171)\end{array}$ & $\begin{array}{l}\text { Biologic failure } \\
(n=506)\end{array}$ & \\
\hline Age, years & $59.9(12.7)$ & $56.9(12.5)$ & $59.4(12.6)$ & $61.3(12.9)$ & $56.4(12.5)$ & 0.072 \\
\hline Female, $n(\%)$ & $496(73.7)$ & $1379(82.2)$ & $368(73.3)$ & $128(74.9)$ & $407(80.4)$ & 0.767 \\
\hline \multirow[t]{2}{*}{ BMI } & $27.0(5.4)$ & $27.1(5.6)$ & $26.8(5.5)$ & $27.7(5.3)$ & $27.5(5.6)$ & \\
\hline & $n=644$ & $n=1597$ & $n=474$ & $n=170$ & & 0.027 \\
\hline \multirow[t]{2}{*}{ RA duration, years } & $7.2(8.2)$ & $12.1(9.1)$ & $7.1(8.5)$ & $7.5(7.3)$ & $11.9(8.6)$ & \\
\hline & $n=669$ & $n=1669$ & $n=499$ & $n=170$ & $n=505$ & 0.036 \\
\hline RA duration, $n(\%)$ & $n=669$ & $n=1669$ & $n=499$ & $n=170$ & $n=505$ & \\
\hline$\leq 2$ years & $239(35.7)$ & $151(9.0)$ & $194(38.9)$ & $45(26.5)$ & $41(8.1)$ & \\
\hline $3-5$ years & $155(23.2)$ & $320(19.2)$ & $109(21.8)$ & $46(27.1)$ & 99 (19.6) & \\
\hline $6-10$ years & $122(18.2)$ & $421(25.2)$ & $84(16.8)$ & $38(22.4)$ & $121(24.0)$ & \\
\hline$>10$ years & $153(22.9)$ & 777 (46.6) & $112(22.4)$ & $41(24.1)$ & $244(48.3)$ & \\
\hline \multirow{2}{*}{ TJC28 } & $9.0(6.5)$ & $10.4(7.2)$ & $9.2(6.3)$ & $8.7(6.9)$ & $9.6(7.4)$ & \\
\hline & $n=633$ & $n=1599$ & $n=463$ & $n=170$ & $n=493$ & 0.104 \\
\hline \multirow[t]{2}{*}{$\mathrm{SJC} 28^{\mathrm{a}}$} & $6.6(5.0)$ & $7.0(5.6)$ & $6.5(5.0)$ & $6.7(5.0)$ & $7.3(5.9)$ & \\
\hline & $n=641$ & $n=1607$ & $n=471$ & $n=170$ & $n=494$ & 0.587 \\
\hline \multirow[t]{2}{*}{$\mathrm{PGA}^{\mathrm{a}}, 100 \mathrm{~mm}$ VAS } & $62.0(20.3)$ & $65.4(19.9)$ & $61.9(20.6)$ & $62.2(19.6)$ & $66.2(19.9)$ & \\
\hline & $n=620$ & $n=1539$ & $n=451$ & $n=169$ & $n=494$ & 0.981 \\
\hline \multirow[t]{2}{*}{$\mathrm{CRP},{ }^{\mathrm{a}} \mathrm{mg} / \mathrm{dL}$} & $16.6(25.9)$ & $21.2(34.7)$ & $15.5(23.8)$ & $19.6(30.8)$ & $23.1(33.1)$ & \\
\hline & $n=590$ & $n=1474$ & $n=431$ & $n=159$ & $n=454$ & 0.157 \\
\hline \multirow[t]{2}{*}{ HAQ-DI } & $1.4(0.7)$ & $1.5(0.7)$ & $1.4(0.7)$ & $1.3(0.7)$ & $1.5(0.7)$ & \\
\hline & $n=579$ & $n=1471$ & $n=436$ & $n=143$ & $n=444$ & 0.028 \\
\hline \multirow[t]{2}{*}{ DAS28 (CRP) ${ }^{a}$} & $4.8(1.1)$ & $5.0(1.1)$ & $4.8(1.1)$ & $4.8(1.1)$ & $5.0(1.2)$ & \\
\hline & $n=568$ & $n=1411$ & $n=410$ & $n=158$ & $n=450$ & 0.754 \\
\hline \multirow[t]{2}{*}{$\mathrm{CDAI}^{\mathrm{a}}$} & $27.5(11.5)$ & $30.0(12.9)$ & $27.3(11.4)$ & $28.1(11.6)$ & $29.7(13.4)$ & \\
\hline & $n=565$ & $n=1388$ & $n=401$ & $n=164$ & $n=488$ & 0.524 \\
\hline \multirow[t]{2}{*}{$\mathrm{SDAI}^{\mathrm{a}}$} & $29.1(11.9)$ & $31.8(13.6)$ & $28.7(11.7)$ & $30.0(12.4)$ & $31.9(14.3)$ & \\
\hline & $n=526$ & $n=1279$ & $n=373$ & $\mathrm{n}=153$ & $n=447$ & 0.332 \\
\hline \multirow[t]{2}{*}{ Radiographic erosion, ${ }^{\mathrm{a}} n(\%)$} & $353(58.2)$ & $1034(71.5)$ & $273(58.3)$ & $80(57.6)$ & $283(76.7)$ & \\
\hline & $n=607$ & $n=1446$ & $n=468$ & $n=139$ & $n=369$ & 0.924 \\
\hline \multirow[t]{2}{*}{ RF positive, ${ }^{\mathrm{a}} n(\%)$} & $415(71.8)$ & $987(71.3)$ & $307(70.4)$ & $108(76.1)$ & $292(72.6)$ & \\
\hline & $n=578$ & $n=1385$ & $n=436$ & $n=142$ & $n=402$ & 0.197 \\
\hline \multirow[t]{2}{*}{ Anti-CCP positive, ${ }^{\mathrm{a}} n(\%)$} & $368(66.2)$ & $884(67.5)$ & $259(65.1)$ & $109(69.0)$ & $295(68.4)$ & \\
\hline & $n=556$ & $n=1309$ & $n=398$ & $n=158$ & $n=431$ & 0.429 \\
\hline$\geq 1$ Comorbidity, $n(\%)$ & $518(77.0)$ & $1226(73.1)$ & $376(74.9)$ & $142(83.0)$ & $385(76.1)$ & 0.036 \\
\hline Hypertension & $257(38.2)$ & $656(39.1)$ & $180(35.9)$ & $77(45.0)$ & $222(43.9)$ & 0.036 \\
\hline Dyslipidemia & $127(18.9)$ & $306(18.2)$ & $108(21.5)$ & $19(11.1)$ & $39(7.7)$ & 0.003 \\
\hline $\begin{array}{l}\text { Number of previous } \\
\text { csDMARDs, }^{b} n(\%)\end{array}$ & & & $n=502$ & $n=171$ & & $<0.001$ \\
\hline$\leq 3$ & $665(98.8)$ & $1561(93.1)$ & $499(99.4)$ & $166(97.1)$ & $451(89.2)$ & \\
\hline$>3$ & $8(1.2)$ & $116(6.9)$ & $3(0.6)$ & $5(2.9)$ & $55(10.8)$ & \\
\hline Previous MTX, $n(\%)$ & $621(92.3)$ & $1552(92.5)$ & $458(91.2)$ & $163(95.3)$ & $448(88.5)$ & 0.094 \\
\hline Previous corticosteroids, $n(\%)$ & $533(79.2)$ & $1386(82.6)$ & $416(82.9)$ & $117(68.4)$ & $346(68.4)$ & $<0.001$ \\
\hline \multicolumn{7}{|l|}{ Previous other csDMARDs, $n(\%)$} \\
\hline \multirow{4}{*}{$\begin{array}{l}\text { Leflunomide } \\
\text { Hydroxychloroquine/chloroquine } \\
\text { Sulfasalazine }\end{array}$} & $278(41.3)$ & $951(56.7)$ & $171(34.1)$ & $107(62.6)$ & $381(75.3)$ & $p<0.001$ \\
\hline & $229(34.0)$ & $681(40.6)$ & $186(37.1)$ & $43(25.1)$ & $152(30.0)$ & $p=0.005$ \\
\hline & $148(22.0)$ & $578(34.5)$ & $90(17.9)$ & $58(33.9)$ & $244(48.2)$ & $p<0.001$ \\
\hline & $n=561$ & $n=1250$ & $n=437$ & $n=124$ & $n=363$ & 0.810 \\
\hline
\end{tabular}


Table 1 (continued)

\begin{tabular}{|c|c|c|c|c|c|c|}
\hline \multirow[b]{2}{*}{ Characteristic } & \multicolumn{2}{|l|}{$\begin{array}{l}\text { Overall } \\
(N=2350)\end{array}$} & \multirow{2}{*}{$\begin{array}{l}\text { Other countries } \\
\text { cohort } \\
(n=1673) \\
\text { Biologic naïve } \\
(n=502)\end{array}$} & \multicolumn{2}{|l|}{$\begin{array}{l}\text { German cohort } \\
(n=677)\end{array}$} & \multirow{2}{*}{$\begin{array}{l}\text { Other countries vs. } \\
\text { German cohort } \\
P \text { value } \\
\text { Biologic naïve }\end{array}$} \\
\hline & $\begin{array}{l}\text { Biologic } \\
\text { naïve } \\
(n=673)\end{array}$ & $\begin{array}{l}\text { Biologic } \\
\text { failure } \\
(n=1677)\end{array}$ & & $\begin{array}{l}\text { Biologic naïve } \\
(n=171)\end{array}$ & $\begin{array}{l}\text { Biologic failure } \\
(n=506)\end{array}$ & \\
\hline Concomitant treatment with & $436(77.7)$ & $947(75.7)$ & $338(77.3)$ & $98(79.0)$ & $265(73.0)$ & \\
\hline $\begin{array}{l}\text { csDMARDs, } n \\
\text { MTX ( } \pm \text { other csDMARDs), } n(\%) \\
\text { Other csDMARDs, } n(\%)\end{array}$ & $125(22.3)$ & $303(24.3)$ & $99(22.7)$ & $26(21.0)$ & $98(27.0)$ & \\
\hline Concomitant corticosteroids, $n(\%)$ & $455(67.6)$ & $1190(71.0)$ & $\begin{array}{l}320(63.7) \\
n=502\end{array}$ & $\begin{array}{l}135(78.9) \\
n=171\end{array}$ & $415(82.0)$ & $<0.001$ \\
\hline
\end{tabular}

Data are mean (SD) unless otherwise stated. Where all patients had available data, the patient number is not shown in the cell

${ }^{a}$ Effectiveness analysis population

${ }^{\mathrm{b}}$ Excluding MTX and corticosteroids

\section{Biologic-naïve patients: German versus pooled other countries cohort}

Among biologic-naïve patients, more patients in the German versus other countries cohort, respectively, were rheumatoid factor (RF) positive (76.1 vs. 70.4\%; $p=0.197$ ), were anticyclic citrullinated peptide (anti-CCP) positive (69.0 vs. $65.1 \% ; p=0.429$ ), had at least one comorbidity (83.0 vs. $74.9 \% ; p=0.036)$, and had a greater mean (SD) number of prior csDMARDs [1.41 (1.03) vs. 1.01 (0.94); $p<0.001]$; higher proportions received abatacept monotherapy (27.5 vs. $12.9 \% ; p<0.001)$ and concomitant corticosteroids (78.9 vs. $63.7 \% ; p<0.001)$. A higher proportion of patients in the other countries cohort versus the German cohort had $\leq 2$ years' duration of RA (38.9 vs. 26.5\%; $p=0.026$ ) and higher proportions received concomitant methotrexate (67.3 vs. $57.3 \% ; p=0.020)$. Similar proportions of patients had radiographic erosions in both cohorts (57.6\% German and $58.3 \%$ other; $p=0.924)$.

\section{Retention rates}

\section{German cohort: Biologic naïve versus biologic failure}

The overall crude abatacept retention rate $(95 \% \mathrm{CI})$ at 2 years in the German cohort was $39.9 \%(36.0,43.7 \%)$ (Fig. 3a). The retention rate did not differ by treatment line: biologic-naïve patients: $42.1 \%(34.3,49.6 \%)$; biologic-failure patients: $39.2 \%$ (34.7, 43.6\%; log-rank test: $p=0.498$ ) (see Figure, Online Resource 1), or by number of failed TNFis: 1 TNFi: 41.9\% (35.2, 48.5\%); $\geq 2$ TNFis: $38.1 \%$ (32.0, 44.2\%).

In the German cohort, discontinuation rates at 2 years for both biologic-naïve and biologic-failure patients, respectively, were higher for inefficacy [37/69 (53.6\%) and 134/207 $(64.7 \%)]$ than for safety reasons $[23 / 69(33.3 \%)$ and 55/207 $(26.6 \%)]$. Other reasons for discontinuation in the two subgroups included patient wish [5/69 (7.2\%) and 11/207 (5.3\%)] and disease major improvement/remission [3/69 (4.3\%) and 4/ $207(1.9 \%)]$, respectively.

\section{Biologic-naïve patients: German versus pooled other countries cohort}

Retention rates over 2 years in biologic-naïve patients were significantly lower in the German cohort than in the pooled other countries cohort (Fig. 3b; log-rank test $p<0.001$ ). A greater proportion of biologic-naïve patients in the German versus other countries cohort, respectively, discontinued for reasons of intolerance or safety [23/69 (33.3\%) vs. 19/128 $(14.8 \%)]$, and a smaller proportion discontinued due to inefficacy $[37 / 69(53.6 \%)$ vs. $84 / 128(65.6 \%)]$.

\section{Clinical outcomes}

\section{German cohort: biologic naïve versus biologic failure}

Good/moderate EULAR response rates were numerically higher in the German cohort in the biologic-naïve than biologic-failure patients, respectively: 71.1 and $61.3 \%$ at 3 months and 85.4 and $79.7 \%$ at 2 years (see Figure, Online Resource 2). In biologic-failure patients at 2 years, good/moderate EULAR response rates were $78.0 \%$ for patients who had failed one previous TNFi and $80.9 \%$ for patients who had failed $\geq 2$ previous TNFis. A numerically greater proportion of biologic-naïve versus biologic-failure patients achieved DAS28 (CRP) remission (57.1 vs. 41.9\%) or DAS28 (ESR) remission (43.2 vs. $28.7 \%$ ) at 2 years. Similarly, the proportion of patients who achieved LDA or remission at 2 years was greater for biologic-naïve versus biologic-failure patients across several criteria: CDAI LDA or remission: 73.6 versus $61.5 \%$, SDAI LDA or remission: 71.4 versus $62.9 \%$; Boolean response was achieved by 20.4 versus $15.3 \%$, respectively. 
Fig. 3 Crude retention rate over 24 months in patients in a the overall German cohort and $\mathbf{b}$ the biologic-naïve German and pooled other countries cohorts. $\mathrm{CI}$, confidence interval a

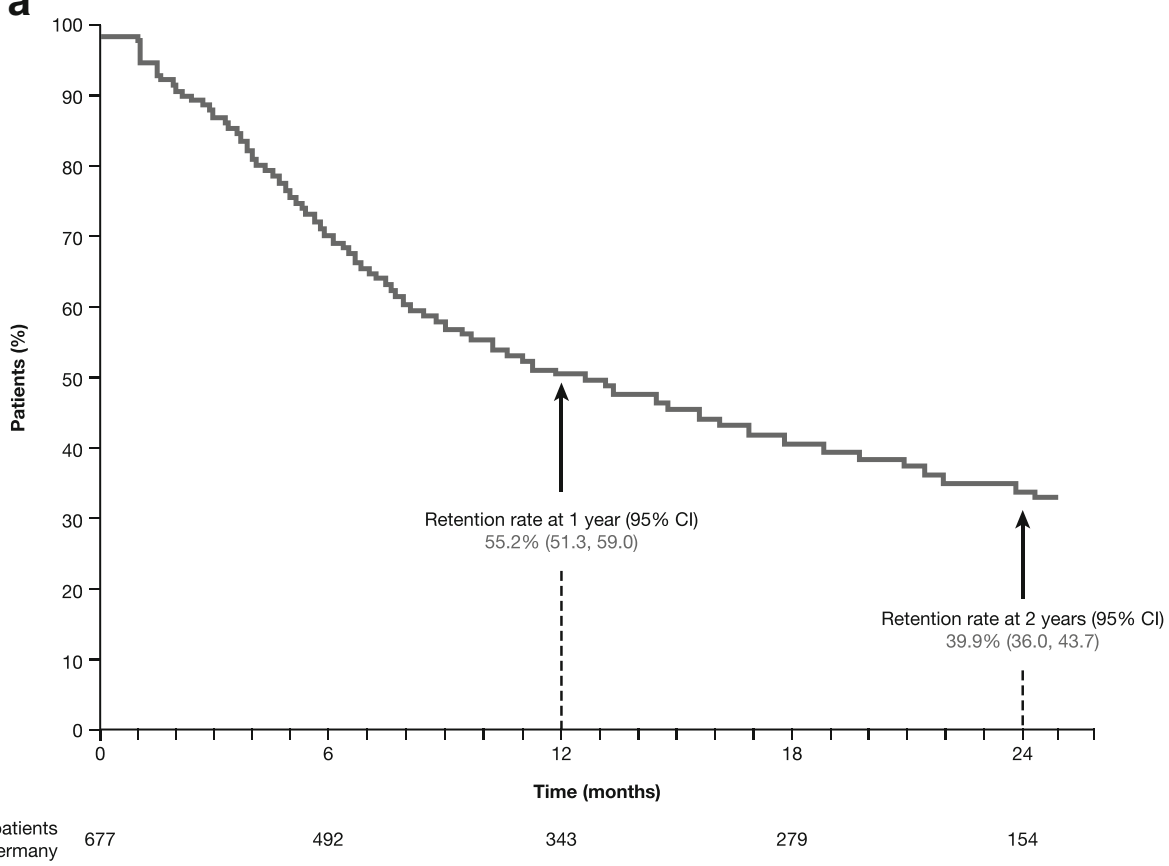

b

- Germany - Other countries

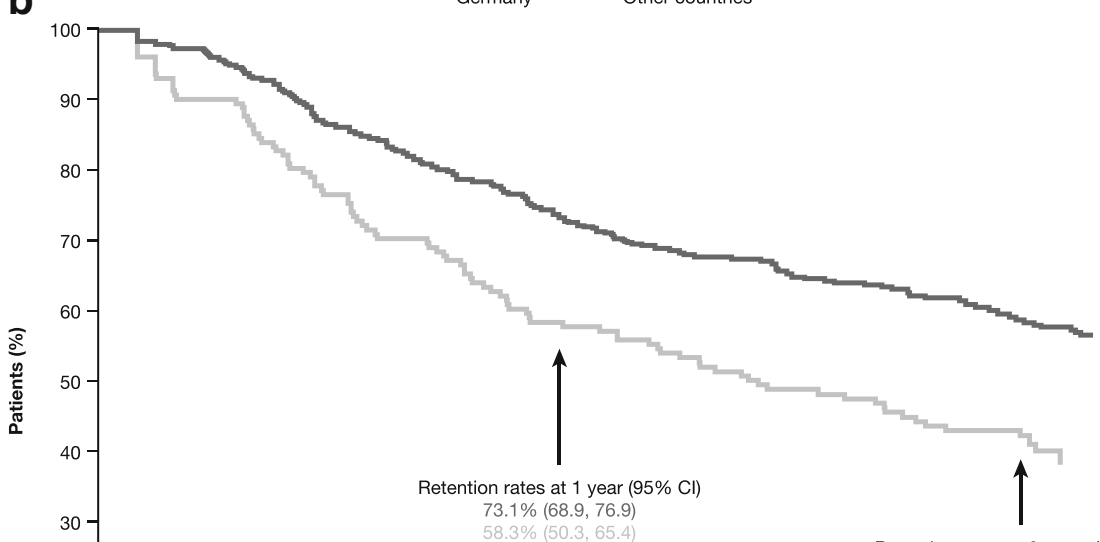

Retention rates at 2 years $(95 \% \mathrm{Cl})$ $58.7 \%(54.1,63.1)$ - $42.1 \%$ - $24.0,49.6$

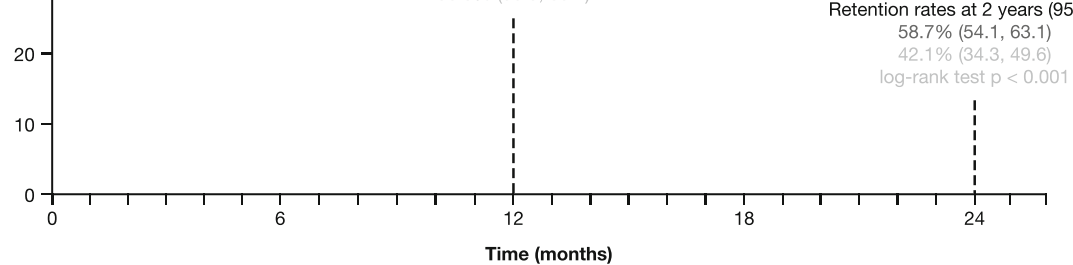

Time (months)

Number of patients

at risk in Germany

$171 \quad 128$

93

75

50

mber of patients at risk in other 502

423

296

189

\section{Biologic-naïve patients: German versus pooled other countries cohort}

Good/moderate EULAR response rates at 2 years in biologic-naïve patients were numerically lower in the German $(85.5 \%)$ than in the other countries cohort $(92.1 \% ; p=$ 0.163 ; Fig. 4). The proportion of biologic-naïve patients in the German cohort achieving LDA or remission at
2 years tended to be numerically lower, with the exception of DAS28 (CRP) remission (57.1 vs. $57.1 \%, p=0.709$ ), than the proportion in the other countries cohort: DAS28 (ESR) remission ( 43.2 vs. $51.3 \%, p=0.608)$, CDAI LDA or remission ( 73.6 vs. $76.1 \%, p=0.715$ ), and SDAI LDA or remission ( 71.4 vs. $73.2 \%, p=0.852$ ); Boolean response was achieved by 20.4 versus $31.3 \%$ of patients, respectively $(p=0.153)$. 


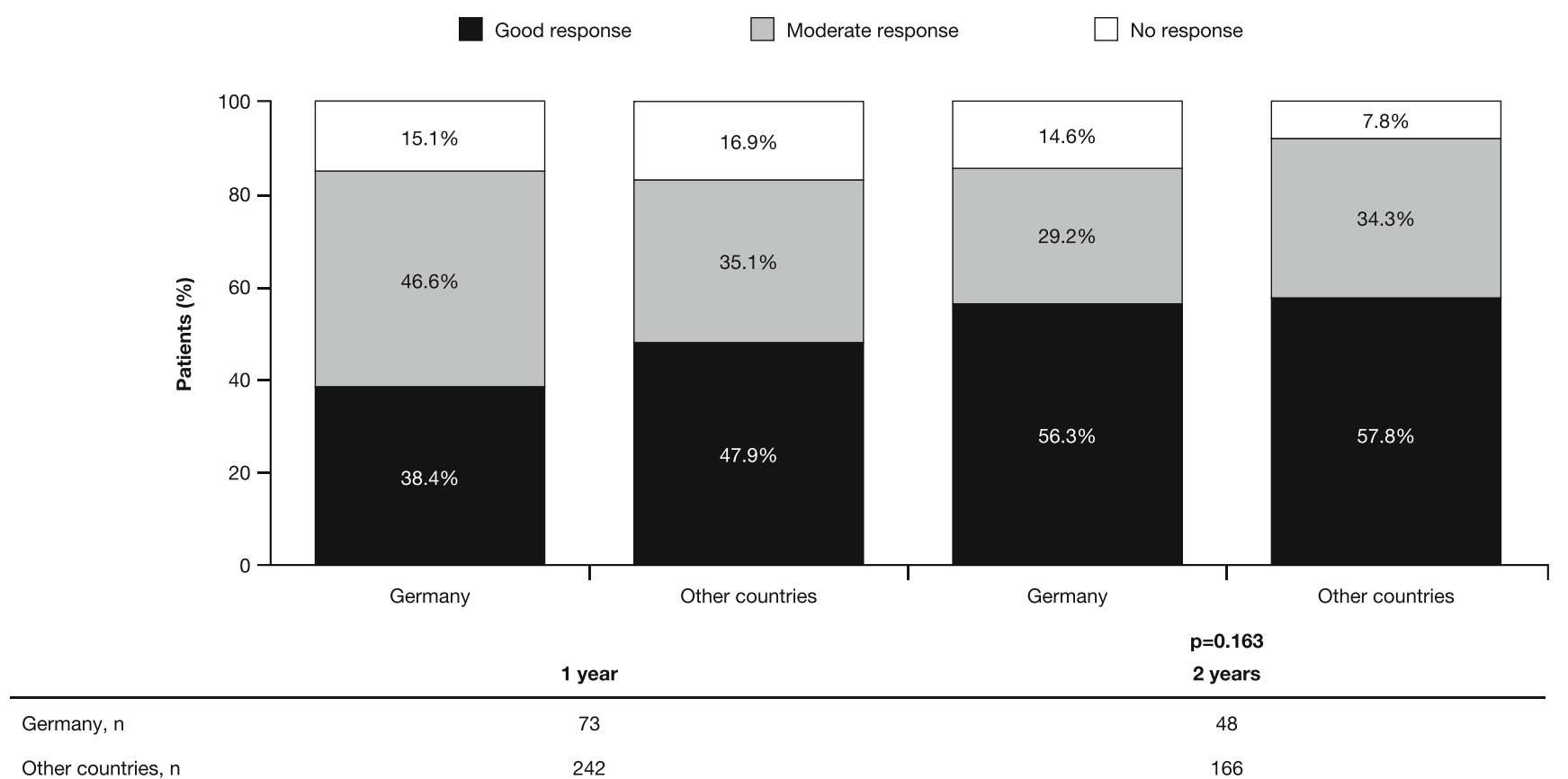

Fig. 4 EULAR response rates based on DAS 28 (ESR; otherwise CRP) with first-line abatacept therapy at 1 and 2 years in the German cohort and pooled other countries cohort. Data as observed in patients on treatment at 24 months; and with relevant baseline clinical data (i.e., clinical

\section{Safety}

\section{German cohort}

In the overall German cohort, 113 SAEs were reported in 52 (7.7\%) patients, none of which resulted in study drug discontinuation; $86 \%$ were considered related to study drug. Three deaths were reported during the study: one due to psychiatric disorders and two due to general disorders. Serious infections were reported in 23 (3.4\%) patients: there was one case of latent tuberculosis, while most others were pneumonia, urinary tract infections, or limb abscesses. Serious immune disorders were reported in two patients (one Crohn's disease, one allergic reaction), and seven cases of malignancies were reported in six patients (one benign breast neoplasm, two Bowen's disease, one malignant melanoma, one neoplasm, one non-Hodgkin's lymphoma, one squamous cell skin carcinoma). In addition, six serious cardiac disorders were reported in four patients (atrial fibrillation, cardiac failure, cardiac arrest, myocardial infarction, cardiovascular disorder, pericarditis), and seven cases of serious vascular disorders were reported in four patients (two hypertension, three peripheral artery occlusive, two thrombosis). No new safety signals were reported.

\section{Other countries cohort}

Safety in the ACTION study has been reported previously [7]. Briefly, in the other countries cohort 268 SAEs were reported assessment performed no later than 8 days after first infusion of abatacept). CRP, C-reactive protein; DAS 28, Disease Activity Score in 28 joints; ESR, erythrocyte sedimentation rate; EULAR, European League Against Rheumatism

in 141/1673 (8.4\%) patients; 94 of these SAEs led to abatacept discontinuation.

\section{Discussion}

In the German cohort of the ACTION study, abatacept retention rates at 2 years were similar in the biologic-naïve and biologic-failure cohorts $(\sim 40 \%)$, and were both lower than in the biologic-naïve cohort of patients from other participating countries (59\%). In contrast, clinical outcomes were generally better in biologic-naïve than biologic-failure patients within the German cohort. A non-specific trend for lower good/moderate EULAR response and LDA/remission rates was seen in biologic-naïve patients from Germany versus those pooled from other countries. Abatacept was well tolerated, and the safety profile was consistent with previous published data, with no new safety signals.

The finding of lower 2-year retention rates in biologicnaïve patients from Germany versus those from other participating countries is interesting. Considerable regional variation in abatacept retention was seen in the overall ACTION study cohort, with 2-year retention rates in biologic-naïve patients ranging from $42.1 \%$ in Germany to $67.8 \%$ in Italy. Furthermore, in biologic-naïve patients, residence in Germany versus Canada, Greece, and Italy was found to be a significant predictor of abatacept discontinuation at 1 and 2 years $[5,8]$. The 2 -year analysis of the biologic-naïve or biologic-failure cohort only of the ACTION study also 
reported a similar finding in biologic-failure patients [4]. In the present analysis, we confirmed that in biologic-naïve patients, not only was retention lower in the German cohort versus the pooled other countries cohort, but that this was accompanied by a trend for poorer clinical outcomes at 2 years.

Variations in abatacept retention rates by country were also reported in an analysis of nine European registries [16]. Geographical differences in retention and response are likely due to numerous factors, including genetic variation [17] and differences in health-care systems. All residents in Germany are legally required to have health insurance; statutory health insurance which covers the cost of most prescription medications with very low out-of-pocket costs is used by most. Despite widespread acceptance of EULAR guidelines for the treatment of RA [1, 18] at a local level [19], the availability, reimbursement and uptake/treatment patterns of newer agents, particularly bDMARDs, does vary greatly between European countries [20-22]. Indeed, lower abatacept retention in countries with greater access to bDMARDs has been described [16], which may partly explain the differences in retention between Germany and other participating countries reported here.

Differences in patient characteristics which could affect the results should also be considered. Compared with the pooled other countries cohort of the ACTION study, a slightly lower proportion of the German cohort was biologic naïve $(25.3 \%$ vs. $30.0 \%$ ). This anomaly may be explained by the high level of accessibility to bDMARDs in Germany; although a minimum level of disease activity is required for bDMARD reimbursement in $86 \%$ of European countries, this is not the case in Germany [22] and so patients may initiate bDMARD treatment earlier in their disease course. Among biologic-naïve patients, the proportion who had received $>3$ prior csDMARDs was significantly higher among those recruited in Germany compared with the other countries, and differences in treatment with specific csDMARDs were noted. Longer disease duration and treatment history, in particular, may have influenced physicians' decisions to change therapy. Patients with RA who have erosions and are seropositive for $\mathrm{RF}$ and/or anti-CCP are generally associated with a poorer prognosis. In ACTION, factors such as RF/anti-CCP seropositivity and comorbidities have been shown to impact abatacept retention [8]. For example, RF/anti-CCP double positivity predicted higher retention and remained associated with higher retention in patients with erosive disease [5]. In the Italian cohort, RF/anti-CCP seropositivity versus double seronegativity was associated with higher retention [23]. Here, we found that a greater proportion of patients was seropositive at baseline in the German cohort than in the pooled other countries cohort, despite retention rates being lower in the German cohort. Of note, abatacept monotherapy was prescribed more frequently in the German than the other countries cohort, yet discontinuations due to inefficacy were less frequent in the German cohort. Biologic monotherapy may have been prescribed for several reasons, including intolerance of or noncompliance with methotrexate [24]. These results demonstrate the complex interplay between many different factors influencing drug retention in RA.

In contrast to findings for the overall ACTION population [8], in the German cohort, there was no significant difference between 2-year retention rates in biologic-naïve versus biologic-failure patients. Prior exposure to biologic agents was also shown to negatively influence abatacept retention in clinical practice by Finckh et al. [16]. In this panEuropean study, variation in retention was explained primarily by differences in access to bDMARDs, rather than patient or disease characteristics. No specific switching criteria for bDMARDs are in place in Germany [22]; therefore, patients may change treatments more frequently, due to factors such as adverse events or early perceived lack of efficacy, than in other locations.

Clinical outcomes for patients in the German cohort of the ACTION study were similar to those in the overall ACTION study cohort [5, 8], with improved outcomes being associated with earlier treatment line. This finding is consistent with abatacept's mechanism of action as an upstream regulator that interferes with the underlying disease process of $\mathrm{T}$ cell activation [25]. Interestingly, there was a trend for lower remission/LDA and EULAR response rates among biologic-naïve patients in the German cohort than in the other countries cohort, although this did not reach statistical significance for any outcome measure. Differences in abatacept retention rates previously observed across European countries were associated with national economic features (e.g., GDP per capita); however, the effects of socioeconomic features (e.g., education level) were less clear [16]. The lower overall retention rate observed in the German cohort compared with that in other countries could be due to preferential or earlier switching of therapy by biologic-naïve patients not reaching LDA/remission based on either patient choice and/or physician expectation, possibly due to the greater access to alternative treatment options in Germany.

These real-world data from local, heterogeneous patient populations that represent patients in routine care are clinically relevant and supplement existing knowledge on the use of abatacept in routine practice. However, the data presented here should be interpreted within the context of the study limitations. Analyses based on real-world studies, although of value, are affected by inherent limitations such as non-randomization, observational trial design, clinician- rather than protocolled treatment decisions, the potential for referral and channeling bias, the lack of an active comparator, and loss of patients to follow-up. Also, these were subgroup analyses of a larger study and analyses were post hoc in nature. Nonetheless, the 
random selection of participating study sites ensured that these were representative of each country.

\section{Conclusions}

Abatacept retention at 2 years in the German cohort from the ACTION study was similar in biologic-naïve versus biologicfailure patients. However, clinical outcomes were generally better in biologic-naïve than biologic-failure patients. In addition, abatacept retention was lower in biologic-naïve patients in the German cohort than in those from other participating countries. This analysis of a national cohort provides important information on local treatment patterns and raises awareness of the potential impact of these on outcomes. Importantly, these findings indicate that data from large international studies may not be directly applicable to individual countries and that this should be taken into consideration when extrapolating data from such studies to the local level. Similarly, data derived from one country are not necessarily generalizable to other countries.

Acknowledgments The authors would like to thank all physicians and patients who participated in the ACTION study. The authors would also like to thank Thilo Klopsch, Rheumatologische Praxis, Neubrandenburg, for his contribution to the study and manuscript development. The study was sponsored by Bristol-Myers Squibb. Professional medical writing and editorial assistance were provided by Fiona Boswell, $\mathrm{PhD}$, and funded by Bristol-Myers Squibb.

Author contributions RA: study conception and design, performing statistical analysis, interpreting data, and critically reviewing and approving the manuscript. EF: study conduct, data collection and interpretation, critical review and manuscript approval. H-ML: data interpretation, critical review, and manuscript approval. HN: study conception and design, collecting data, performing statistical analysis, interpreting data, and critically reviewing and approving the manuscript. REV: data interpretation, critical review, and manuscript approval. MC: performing statistical analysis, interpreting data, and critically reviewing and approving the manuscript. YE: performing statistical analysis, interpreting data, and critically reviewing and approving the manuscript. CR: study conception and design, managing the study, data interpretation, critical review, and manuscript approval.

Source of funding This study was funded by Bristol-Myers Squibb.

Data availability Bristol-Myers Squibb policy on data sharing may be found at https://www.bms.com/researchers-and-partners/independentresearch/data-sharing-request-process.html

\section{Compliance with ethical standards}

The study was conducted in accordance with the Declaration of Helsinki, [12] the International Conference for Harmonization Guideline for Good Clinical Practice, [13], and the Good Epidemiological Practice guideline, [14] with local institutional review board/independent ethics committee approval. All patients provided written informed consent in accordance with local laws.
Conflict of interest RA: research grants: Bristol-Myers Squibb. EF: honoraria and grant support: Bristol-Myers Squibb, Novartis, Pfizer, Roche, MSD, AbbVie, Lilly, and Sanofi. H-ML: consulting fees: AbbVie, Bristol-Myers Squibb, Roche-Chugai, UCB, MSD, GSK, Sobi, Medac, Novartis, Janssen-Cilag, AstraZeneca, Pfizer, and Actelion. HN: consulting fees: AbbVie, Bristol-Myers Squibb, Celgene, Janssen, Lilly, MSD, Novartis, Pfizer, Roche and UCB. REV: honoraria and/or grant support: AbbVie, Bristol-Myers Squibb, Celgene, MSD, Novartis, Pfizer, Roche, Sanofi, and Takeda. MC: employment: BristolMyers Squibb. YE: consultancy fees: Bristol-Myers Squibb. CR: employee and shareholder: Bristol-Myers Squibb. All authors have full control of all primary data and agree to journal review of data, if requested.

Open Access This article is distributed under the terms of the Creative Commons Attribution 4.0 International License (http:// creativecommons.org/licenses/by/4.0/), which permits unrestricted use, distribution, and reproduction in any medium, provided you give appropriate credit to the original author(s) and the source, provide a link to the Creative Commons license, and indicate if changes were made.

\section{References}

1. Smolen JS, Landewe R, Breedveld FC, Buch M, Burmester G, Dougados M, Emery P, Gaujoux-Viala C, Gossec L, Nam J, Ramiro S, Winthrop K, de Wit M, Aletaha D, Betteridge N, Bijlsma JW, Boers M, Buttgereit F, Combe B, Cutolo M, Damjanov N, Hazes JM, Kouloumas M, Kvien TK, Mariette X, Pavelka K, van Riel PL, Rubbert-Roth A, Scholte-Voshaar M, Scott DL, Sokka-Isler T, Wong JB, van der HD (2014) EULAR recommendations for the management of rheumatoid arthritis with synthetic and biological disease-modifying antirheumatic drugs: 2013 update. Ann Rheum Dis 73(3):492-509

2. Smolen JS (2016) Treat-to-target as an approach in inflammatory arthritis. Curr Opin Rheumatol 28(3):297-302

3. Du Pan SM, Dehler S, Ciurea A, Ziswiler HR, Gabay C, Finckh A (2009) Comparison of drug retention rates and causes of drug discontinuation between anti-tumor necrosis factor agents in rheumatoid arthritis. Arthritis Rheum 61(5):560-568

4. Nüßlein HG, Alten R, Galeazzi M, Lorenz HM, Nurmohamed MT, Bensen WG, Burmester GR, Peter HH, Peichl P, Pavelka K, Chartier M, Poncet C, Rauch C, Le BM (2016) Efficacy and prognostic factors of treatment retention with intravenous abatacept for rheumatoid arthritis: 24-month results from an international, prospective, real-world study. Clin Exp Rheumatol 34(3):489-499

5. Alten R, Mariette X, Lorenz HM, Galeazzi M, Cantagrel A, Nusslein HG, Chartier M, Elbez Y, Rauch C, Le Bars M (2017) Real-world predictors of 12-month intravenous abatacept retention in patients with rheumatoid arthritis in the ACTION observational study. RMD Open 3(2):e000538. https://doi.org/10.1136/rmdopen2017-000538

6. Nüßlein H, Alten R, Galeazzi M, Lorenz HM, Boumpas D, Nurmohamed MT, Bensen WG, Burmester GR, Peter HH, Rainer F, Pavelka K, Chartier M, Poncet C, Rauch C, Le Bars M (2014) Real-world effectiveness of abatacept for rheumatoid arthritis treatment in European and Canadian populations: a 6-month interim analysis of the 2-year, observational, prospective ACTION study. BMC Musculoskelet Disord 15(1):14

7. Alten R, Mariette X, Lorenz HM, Nusslein H, Galeazzi M, Navarro F, Chartier M, Heitzmann J, Poncet C, Rauch C, Le Bars M (2019) Predictors of abatacept retention over 2 years in patients with rheumatoid arthritis: results from the real-world ACTION study. Clin Rheumatol. https://doi.org/10.1007/s10067-019-04449-w 
8. Alten R, Lorenz HM, Mariette X, Nüßlein HG, Galeazzi M, Navarro F, Chartier M, Elbez Y, Rauch C, Le Bars M Abatacept Retention Rates, Overall and By Participating Country, and Prognostic Factors of Retention in Patients with RA: 2-Year Results from a Real-World Observational Study. In: 2017 ACR/ ARHP Annual Meeting, San Diego, CA, USA, November 4-8, 2017 2017. p 1468

9. Arnett FC, Edworthy SM, Bloch DA, McShane DJ, Fries JF, Cooper NS, Healey LA, Kaplan SR, Liang MH, Luthra HS (1988) The American Rheumatism Association 1987 revised criteria for the classification of rheumatoid arthritis. Arthritis Rheum 31(3):315-324

10. Orencia $250 \mathrm{mg}$ powder for concentrate for solution for infusion. (2017). http://www.medicines.org.uk/emc/medicine/19714/SPC/. Accessed 21 May 2018

11. Bristol-Myers Squibb Canada (2017) Orencia (abatacept) product monograph. http://www.bms.com/assets/bms/ca/documents/ productmonograph/ORENCIA EN PM.pdf. Accessed 21 May 2018

12. World Medical Association Declaration of Helsinki Recommendations guiding physicians in biomedical research involving human subjects (1997). JAMA 277(11):925-926

13. ICH Harmonised Tripartite Guideline: Guideline for Good Clinical Practice (2001). J Postgrad Med 47(3):199-203

14. International Epidemiological Association (2007) Good Epidemiological Practice (GEP): IEA Guidelines for Proper Conduct in Epidemiologic Research. IEA-European Federation. http://ieaweb.org/good-epidemiological-practice-gep/. Accessed 21 May 2018

15. Felson DT, Smolen JS, Wells G, Zhang B, van Tuyl LH, Funovits J, Aletaha D, Allaart CF, Bathon J, Bombardieri S, Brooks P, Brown A, Matucci-Cerinic M, Choi H, Combe B, de Wit M, Dougados M, Emery P, Furst D, Gomez-Reino J, Hawker G, Keystone E, Khanna D, Kirwan J, Kvien TK, Landewe R, Listing J, Michaud K, MartinMola E, Montie P, Pincus T, Richards P, Siegel JN, Simon LS, Sokka T, Strand V, Tugwell P, Tyndall A, van der Heijde D, Verstappen S, White B, Wolfe F, Zink A, Boers M (2011) American College of Rheumatology/European League against Rheumatism provisional definition of remission in rheumatoid arthritis for clinical trials. Ann Rheum Dis 70:404-413

16. Finckh A, Neto D, Iannone F, Loza E, Lie E, van Riel P, Hetland ML, Pavelka K, Gottenberg JE, Canhão H, Mariette X, Turesson C (2015) The impact of patient heterogeneity and socio-economic factors on abatacept retention in rheumatoid arthritis across nine European countries. RMD Open 1:e000040

17. Viatte S, Barton A (2017) Genetics of rheumatoid arthritis susceptibility, severity, and treatment response. Semin Immunopathol 39(4):395-408. https://doi.org/10.1007/s00281-017-0630-4

18. Smolen JS, Landewé R, Bijlsma J, Burmester G, Chatzidionysiou K, Dougados M, Nam J, Ramiro S, Voshaar M, van Vollenhoven R, Aletaha D, Aringer M, Boers M, Buckley CD, Buttgereit F, Bykerk V, Cardiel M, Combe B, Cutolo M, van Eijk-Hustings Y, Emery P, Finckh A, Gabay C, Gomez-Reino J, Gossec L, Gottenberg JE, Hazes JM, Huizinga T, Jani M, Karateev D, Kouloumas M,
Kvien T, Li Z, Mariette X, McInnes I, Mysler E, Nash P, Pavelka K, Poor G, Richez C, van Riel P, Rubbert-Roth A, Saag K, da Silva J, Stamm T, Takeuchi T, Westhovens R, de Wit M, van der Heijde D (2017) EULAR recommendations for the management of rheumatoid arthritis with synthetic and biological disease-modifying antirheumatic drugs: 2016 update. Ann Rheum Dis 76(6):960-977. https://doi.org/10.1136/annrheumdis-2016-210715

19. Albrecht K, Kruger K, Wollenhaupt J, Alten R, Backhaus M, Baerwald C, Bolten W, Braun J, Burkhardt H, Burmester GR, Gaubitz M, Gause A, Gromnica-Ihle E, Kellner H, Kuipers J, Krause A, Lorenz HM, Manger B, Nusslein H, Pott HG, RubbertRoth A, Schneider M, Specker C, Schulze-Koops H, Tony HP, Wassenberg S, Muller-Ladner U, German Society of R (2014) German guidelines for the sequential medical treatment of rheumatoid arthritis with traditional and biologic disease-modifying antirheumatic drugs. Rheumatol Int 34:1-9. https://doi.org/10.1007/ s00296-013-2848-3

20. Emery P, Solem C, Majer I, Cappelleri JC, Tarallo M (2015) A European chart review study on early rheumatoid arthritis treatment patterns, clinical outcomes, and healthcare utilization. Rheumatol Int 35(11):1837-1849. https://doi.org/10.1007/s00296-015-3312-3

21. Putrik P, Ramiro S, Kvien TK, Sokka T, Pavlova M, Uhlig T, Boonen A (2014) Inequities in access to biologic and synthetic DMARDs across 46 European countries. Ann Rheum Dis 73(1): 198-206

22. Putrik P, Ramiro S, Kvien TK, Sokka T, Uhlig T, Boonen A Equity in Clinical Eligibility Criteria for RAtWG (2014) Variations in criteria regulating treatment with reimbursed biologic DMARDs across European countries. Are differences related to country's wealth. Ann Rheum Dis 73(11):2010-2021. https://doi.org/10. 1136/annrheumdis-2013-203819

23. Galeazzi M, Alten R, Chartier M, Elbez Y, Fusaro E, Le Bars M, Lorenz HM, Pagano Mariano G, Muratore M, Nüßlein HG, Patanè G (2018) Retention and clinical response to abatacept in patients with rheumatoid arthritis: an Italian perspective. Clin Exp Rheumatol 36(5):935-936

24. Buckley F, Finckh A, Huizinga TW, Dejonckheere F, Jansen JP (2015) Comparative efficacy of novel DMARDs as monotherapy and in combination with methotrexate in rheumatoid arthritis patients with inadequate response to conventional DMARDs: a network meta-analysis. J Manag Care Spec Pharm 21(5):409-423. https://doi.org/10.18553/jmcp.2015.21.5.409

25. Cutolo M, Sulli A, Paolino S, Pizzorni C (2016) CTLA-4 blockade in the treatment of rheumatoid arthritis: an update. Expert Rev Clin Immunol 12(4):417-425

Publisher's note Springer Nature remains neutral with regard to jurisdictional claims in published maps and institutional affiliations. 